Published in final edited form as:

Biochemistry. 2007 June 26; 46(25): 7655-7664.

\title{
Insights into the Mechanism of Flavoprotein-Catalyzed Amine Oxidation from Nitrogen Isotope Effects on the Reaction of $\mathbf{N}$ - Methyltryptophan Oxidase ${ }^{\dagger}$
}

\author{
Erik C. Ralph $\ddagger$, Jennifer S. Hirschi§, Mark A. Anderson II, W. Wallace ClelandI, Daniel A. \\ Singleton $\S^{, *}$, and Paul F. Fitzpatrick ${ }^{\ddagger}, \S^{,}{ }^{*}$ \\ ¥ Department of Biochemistry and Biophysics, Texas A\&M University, College Station TX 77843-2128 \\ $\S$ Department of Chemistry, Texas A\&M University, College Station TX 77843-2128 \\ || Institute for Enzyme Research and Department of Biochemistry University of Wisconsin, Madison, WI
}

\section{Abstract}

The mechanism of $N$-methyltryptophan oxidase, a flavin-dependent amine oxidase from Escherichia coli, was studied using a combination of kinetic isotope effects and theoretical calculations.

The ${ }^{15}\left(\mathrm{k}_{\mathrm{cat}} / \mathrm{K}_{\mathrm{m}}\right)$ kinetic isotope effect for sarcosine oxidation is $\mathrm{pH}$-dependent with a limiting value of 0.994-0.995 at high pH. Density functional theory (DFT) calculations on model systems were used to interpret these isotope effects. The isotope effects are inconsistent with proposed mechanisms involving covalent amine-flavin adducts but cannot by themselves conclusively distinguish between some discrete electron-transfer mechanisms and a direct hydride-transfer mechanism, although the latter mechanism is more consistent with the energetics of the reaction.

Flavin-dependent amine oxidases and dehydrogenases catalyze the oxidative deamination of primary amines and the oxidative dealkylation of secondary amines. These enzymes are ubiquitous in nature and are involved in a myriad of biological activities. For example, glycine oxidase is involved in thiamin biosynthesis in microorganisms (1), while the recently discovered lysine-specific histone demethylase is involved in regulation of transcription in humans (2). The ubiquity and functional diversity of this family of enzymes underlie its importance and have prompted many structural and biochemical studies. To date,

flavoenzymes that catalyze amine oxidations have fallen into two structural groups. One class includes D-amino acid oxidase (3), monomeric sarcosine oxidase (MSOX)1 (4) and glycine oxidase (1), with monoamine oxidase (MAO) B (5) polyamine oxidase (6), lysine-specific demethylase-1 (7) and L-amino acid oxidase (8) forming a separate structural class. While a number of these enzymes have been the subject of kinetic, spectroscopic, and structural studies, only in the case of D-amino acid oxidase have mechanistic (9) and structural studies (3) led to a consensus that the reaction involves hydride transfer. The chemical mechanism of the remaining amine oxidases is still debated.

$N$-Methyltryptophan oxidase (MTOX) catalyzes the oxidative demethylation of $N$-methyl amino acids (Scheme 1), with a preference for bulky hydrophobic substrates such as $N$-methylL-tryptophan (10). Although the three dimensional structure of MTOX is unavailable, it shares $41 \%$ sequence identity with MSOX and the active site residues are conserved, establishing that

\footnotetext{
$\dagger$ This work was supported by grants GM58698 (PFF), GM45617 (DAS), and GM18938 (WWC) from the National Institutes of Health. *Corresponding authors. D.A.S.: phone, 979-845-9166; fax 979-845-0653; e-mail, singleton@ mail.chem.tamu.edu. P.F.F.: phone, 979-845-5487; fax 979-845-4946; e-mail, fitzpat@tamu.edu

Supporting Information Available: Energies and full geometries of all calculated structures. This material is available free of charge via the Internet at http://pubs.acs.org.
} 
it can be assigned to the same structural class. As shown in Scheme 2, a variety of mechanisms have been proposed for substrate oxidation by MTOX (11). Similar mechanisms have been proposed for other flavin-dependent amine demethylases and for flavin-dependent amine oxidation in general (for recent reviews, see references (12) and (13)). Therefore, investigation of the chemical mechanism of MTOX should aid in understanding a number of important flavoenzymes.

The simplest mechanism in Scheme 2 is a one-step hydride transfer from the methyl group of the substrate $\mathbf{1}$ to the flavin to form iminium product $\mathbf{2}$ directly. In a second possibility, the substrate nitrogen attacks the flavin cofactor at $\mathrm{C}^{4 \mathrm{a}}$ or $\mathrm{N}^{5}$ to form a covalently bound flavin adduct 3 . This is followed by the loss of a proton from the substrate methyl carbon and elimination to give the final products. In a variation of this mechanism, the addition and elimination occur in a single step (14). A third possible mechanism involves two separate oneelectron transfer steps. The initial transfer of an electron to the flavin from $\mathbf{1}$ forms a flavin semiquinone and aminium cation radical $\mathbf{4}$, which is then further oxidized by separate proton and electron transfers via $\mathbf{5}$. In variations of the electron-transfer mechanism, proton and electron transfers are combined into a single hydrogen transfer step, either forming $\mathbf{5}$ directly from 1 or forming 2 directly from 4 .

We have previously used deuterium kinetic isotope effects to show that $\mathrm{CH}$ bond cleavage is fully rate-limiting for sarcosine turnover by MTOX (15). Moreover, no intermediate flavin species is observable when the reduction of the flavin in MTOX is monitored using a stoppedflow spectrophotometer. These results are fully consistent with the hydride-transfer mechanism and put limitations on the covalent-adduct and electron-transfer mechanisms, each of which involve an intermediate flavin species prior to $\mathrm{CH}$ bond cleavage. If an intermediate flavin species is indeed formed, it must be formed reversibly and it must be significantly higher in energy than its precursor, so that less than 5\% of the enzyme is in the form of the postulated intermediate species at any time in the reaction.

Although the previous results are consistent with a hydride-transfer mechanism, they do not by themselves rule out the alternative mechanisms. In the present study, ${ }^{15} \mathrm{~N}$ isotope effects and model theoretical calculations have been utilized to further probe the mechanism of sarcosine oxidation by MTOX. The results firmly exclude mechanisms involving covalent adducts.

\section{EXPERIMENTAL PROCEDURES}

\section{Materials}

Sarcosine ( $N$-methylglycine) was purchased from Sigma Chemical Company (St. Louis, MO) or ACROS Organics (Morris Plains, NJ). MTOX was purified on a HiTrap Chelating HP column as previously described (15).

\section{Sample preparation}

Sarcosine consumption reactions were run over a pH range of 7.5 to 9.8. Starting conditions were typically $0.2 \mathrm{M}$ sarcosine and $100 \mu \mathrm{g} \mathrm{mL}^{-1}$ catalase in $10 \mathrm{~mL}$. Samples were buffered using potassium phosphate $(\mathrm{pH} 7.5)$, potassium pyrophosphate $(\mathrm{pH} 8-9)$ or sarcosine $(\mathrm{pH}>$ 9). A significant decrease in the sample $\mathrm{pH}$ typically occurred as the reaction progressed. Therefore, the $\mathrm{pH}$ was frequently monitored and adjusted with potassium hydroxide as necessary. The samples were generally kept within $0.1 \mathrm{pH}$ units of the desired value. Additional MTOX was added periodically to keep the reaction progressing. Reactions were stirred in the dark at $25^{\circ} \mathrm{C}$ with wet $100 \%$ oxygen blowing over the surface. Reaction progress was monitored by HPLC as follows: A $100 \mu \mathrm{L}$ sample was withdrawn and mixed with $500 \mu \mathrm{L}$ of 
$50 \mathrm{mM}$ monobasic potassium phosphate in $50 \% \mathrm{MeCN}$. Protein was removed by either filtering the sample through a $0.20 \mathrm{~km}$ nylon filter or by centrifugation for $20 \mathrm{~min}$ at $21000 \times$ $\mathrm{G}$. The sample was then loaded onto a Waters $\mu$ Bondapak-NH2 column $(3.9 \times 300 \mathrm{~mm})$ with a $100 \mu \mathrm{L}$ loop and eluted isocratically with $77 \% \mathrm{MeCN}, 5 \mathrm{mM}$ potassium phosphate, $\mathrm{pH}^{*} 7.2$, at $3 \mathrm{~mL} \mathrm{~min}{ }^{-1}$. Sarcosine, glycine, and formaldehyde were detected by monitoring the absorbance at $210 \mathrm{~nm}$. The fractional consumption of sarcosine was determined by comparing the peak areas of sarcosine and glycine to standard curves prepared using commercially available compounds. When sufficient sarcosine had been oxidized, reactions were quenched by the addition of hydrochloric acid to yield a $\mathrm{pH}$ below 1 . Protein was then removed by centrifugation. Samples were dried using a rotary evaporator and resuspended in 4 to $5 \mathrm{~mL}$ of water. Acetonitrile was added to yield 40 to $50 \%$, and the $\mathrm{pH}$ was adjusted to $\mathrm{pH}^{*} 7$. Samples $(1 \mathrm{~mL})$ were loaded onto a preparative Waters $\mu$ Bondapak $^{-} \mathrm{NH}_{2}$ column $(7.8 \times 300 \mathrm{~mm})$ and eluted at $4 \mathrm{~mL} \mathrm{~min}{ }^{-1}$ with $77 \% \mathrm{MeCN}, 2.5 \mathrm{mM}$ potassium phosphate, $\mathrm{pH}^{*} 7.2$ while collecting $8 \mathrm{~mL}$ fractions. The sarcosine and glycine fractions were separately pooled, dried on a rotary evaporator, resuspended in water, lyophilized, and submitted for isotopic ratio mass spectrometry (IRMS) analysis.

\section{IRMS analysis}

Quartz tubes $(0.9 \mathrm{~cm}$ o.d. $\times 0.7 \mathrm{~cm}$ i.d. $\times 24 \mathrm{~cm}$ long $)$ were charged with the sample of interest (either 8-10 mg of sarcosine or 6-8 mg of glycine), diatomaceous earth (100 mg), $\mathrm{CuO}(3-4$ $\mathrm{g})$, and $\mathrm{Cu}(500 \mathrm{mg})$. The tubes were placed under vacuum, flame sealed, and combusted at $850{ }^{\circ} \mathrm{C}$. The $\mathrm{N}_{2}$ produced was distilled on a high vacuum line through two $-78{ }^{\circ} \mathrm{C}$ traps and one $-196^{\circ} \mathrm{C}$ trap, and then trapped on molecular sieves at $-196{ }^{\circ} \mathrm{C}$. The isotopic composition of the $\mathrm{N}_{2}$ was determined using a Finnegan delta $\mathrm{E}$ isotope ratio mass spectrometer.

\section{Data analysis}

The observed ${ }^{15} \mathrm{~N}$ isotope effects were calculated from equations 1 and 2 , where $f$ is the final fractional consumption of sarcosine, $R_{0}$ is the abundance of ${ }^{15} \mathrm{~N}$ in sarcosine prior to enzyme addition, and $\mathrm{R}_{\mathrm{P}}$ and $\mathrm{R}_{\mathrm{S}}$ are the abundances of ${ }^{15} \mathrm{~N}$ in the enzymatically formed glycine and remaining sarcosine respectively. The $\mathrm{pH}$ dependence of the observed ${ }^{15} \mathrm{~N}$ effects was fit to equation 3 using KaleidaGraph (Synergy Software, Reading, PA). Here, the $\mathrm{pK}_{\mathrm{a}}$ is for the sarcosine amine, ${ }^{15} \mathrm{~K}_{\mathrm{eq}}$ is the equilibrium effect for amine deprotonation, and ${ }^{15} \mathrm{~K}$ is the intrinsic, $\mathrm{pH}$-independent isotope effect.

$$
\begin{gathered}
15\left(\mathrm{k}_{\text {cat }} \mid \mathrm{K}_{\mathrm{m}}\right)=\frac{\log (1-f)}{\log \left[(1-f)\left(R_{S} \mid R_{0}\right)\right]} \\
15\left(\mathrm{k}_{\text {cat }} \mid \mathrm{K}_{\mathrm{m}}\right)=\frac{\log (1-f)}{\log \left(1-f R_{P} \mid R_{0}\right)} \\
15\left(\mathrm{k}_{\text {cat }} / \mathrm{K}_{\mathrm{m}}\right)_{\text {obs }}={ }^{15} \mathrm{k}^{*}\left[1+\left({ }^{15} \mathrm{~K}_{\text {eq }}-1\right) /\left(1+10^{\mathrm{pH}-\mathrm{pKa})]}\right.\right.
\end{gathered}
$$

\section{Theoretical calculations}

The mechanisms of Scheme 2 were explored using the parent alloxazine $\mathbf{6}$ as a model for FAD and using dimethylamine as a model for the $N$-methyl amino acid substrates of MTOX. (The pKa's of the $\mathrm{Me}_{2} \mathrm{NH}_{2}{ }^{+}$and $\mathrm{MeNH}_{2}{ }^{+} \mathrm{CH}_{2} \mathrm{CO}_{2}-$ are 10.64 and 10.01, respectively, and the calculated methyl-group C-H bond strengths for $\mathrm{Me}_{2} \mathrm{NH}$ and sarcosine are 88.6 and $89.2 \mathrm{kcal} /$ mol, respectively.) Ground-state and transition structures were fully optimized in B3LYP/6-31 $+\mathrm{G}^{* *}$ calculations using Gaussian 03 (16). Unrestricted calculations (UB3LYP) were employed for odd-electron species. A vibrational frequency analysis was performed on all stationary points. To allow for solvation effects, structures were also optimized using an 
Onsager solvent model for water (17) with single-point energies calculated using a PCM solvent model (18) and Bondi atomic radii (19). Equilibrium and kinetic isotope effects were calculated based on the Onsager solvent-model structures from the scaled (0.9614) frequencies at $25{ }^{\circ} \mathrm{C}$ using the statistical mechanics/conventional transition state theory formulation of Bigeleisen and Mayer (20,21). Tunneling corrections were applied using the one-dimensional Wigner model (22).

\section{RESULTS}

\section{${ }^{15} \mathrm{~N}$ Isotope Effects}

To determine ${ }^{15} \mathrm{~N}$ isotope effects for MTOX, sarcosine solutions were oxidized by the enzyme to $30-50 \%$ conversion, yielding a mixture of sarcosine, glycine, and formaldehyde. The sarcosine and glycine were separated by HPLC and analyzed for their ${ }^{15} \mathrm{~N} /{ }^{14} \mathrm{~N}$ content using IRMS. Sarcosine consumption reactions were conducted over a $\mathrm{pH}$ range of 7.5 to 9.8 , with enzyme instability prohibiting reactions at higher $\mathrm{pH}$. The observed ${ }^{15} \mathrm{~N}$ isotope effects were calculated using equations 1 and 2 , as described above.

As shown in Table 1, the observed isotope effects are $\mathrm{pH}$-dependent, starting at a value greater than 1 and then decreasing with increasing $\mathrm{pH}$. The $\mathrm{pH}$ dependence of the observed isotope effects is not due to changes in either the rate-limiting step or the transition state structure, as the observed deuterium kinetic isotope effect is $\mathrm{pH}$-independent (15). It can therefore be attributed to the ${ }^{15} \mathrm{~N}$ equilibrium isotope effect on sarcosine deprotonation (see below).

For each sarcosine consumption reaction, ${ }^{15}\left(\mathrm{k}_{\mathrm{cat}} / \mathrm{K}_{\mathrm{m}}\right)_{\text {obs }}$ values were obtained independently from the sarcosine remaining and from the glycine produced. A comparison of the two values serves as an internal control for any artifactual ${ }^{15} \mathrm{~N}$ fractionation that may result from sample preparation. As shown in Table 1, the isotope effect calculated from the residual sarcosine was always slightly higher than that calculated from the product glycine at any given $\mathrm{pH}$. The first reaction at $\mathrm{pH} 8.5$ showed the largest difference in ${ }^{15}\left(\mathrm{k}_{\mathrm{cat}} / \mathrm{K}_{\mathrm{m}}\right)_{\mathrm{obs}}$ values $(0.0023)$. Therefore, a second reaction was run at the same $\mathrm{pH}$ which yielded a much smaller difference in ${ }^{15}\left(\mathrm{k}_{\text {cat }} /\right.$ $\left.\mathrm{K}_{\mathrm{m}}\right)_{\text {obs }}$ values (0.0004). Importantly, the averages of the isotope effects determined from substrate and product are nearly identical for both reactions (1.0168 and 1.0169). These observations are inconsistent with random errors in measuring ${ }^{15} \mathrm{~N}$ fractionation.

Random ${ }^{15} \mathrm{~N}$ fractionation should affect the two determinations of ${ }^{15}\left(\mathrm{k}_{\mathrm{cat}} / \mathrm{K}_{\mathrm{m}}\right)_{\mathrm{obs}}$ independently and would therefore alter the measured average isotope effects. Furthermore, random errors are unlikely to result in a consistent increase of one value relative to the other. Instead, a small systematic error in the determination of the percent conversion from either the substrate or the product is consistent with the above observations. Most importantly, the differences between the values calculated from sarcosine and glycine are small enough that mechanistic conclusions are the same using either the sarcosine or the glycine-derived values or their averages.

\section{Theoretical Mechanisms}

No simple theoretical model can adequately represent the energy surface for the enzymatic reaction in solution. Instead, our goal was to calculationally explore a range of mechanistic models for the amine oxidation mechanisms of Scheme 2 in order to interpret the experimental ${ }^{15} \mathrm{~N}$ kinetic isotope effect. This by itself is complicated due to the involvement of charged intermediates. Gas-phase calculations on mechanistic steps involving charge separation or annihilation are dominated by Coulombic effects, distorting the calculated transition structures for such steps. To mitigate this problem, the calculational models here employ either cationic species (avoiding zwitterionic charge separation), an implicit solvent model, or a combination of the two. The calculational models cannot mimic the specific 
interactions employed by the enzyme in promoting the reaction, but should serve as a guide for interpreting the isotope effects.

Scheme 3 shows the calculational model reactions for direct hydride transfer. Relative energies (kcal/mol versus starting materials) and selected interatomic distances (in $\AA$ ) are shown in the scheme for the structures obtained employing a solvation model (PCM/B3LYP/6-31+G**// Onsager/B3LYP/6-31+G** + zpe), along with corresponding energies and distances in brackets obtained with gas-phase calculations. Transition structure 7 was located for the transfer of a hydride from dimethylamine to the neutral FAD model $\mathbf{6}$, affording a complex of the $N$-methyliminium cation with $6-5-\mathrm{H}^{-}$(the model for $\mathrm{FADH}^{-}$). The favored orientation shown minimizes charge separation between the incipient ions and leads to a very tight anioncation complex. Pulling apart these ions in the gas phase is prohibitively uphill (accounting for most of the $\approx 114 \mathrm{kcal} / \mathrm{mol}$ to form separate gas-phase product ions), but the barrier for hydride transfer to form an ion pair is only $26.3 \mathrm{kcal} / \mathrm{mol}\left(\mathrm{B} 3 \mathrm{LYP} / 6-31+\mathrm{G}^{* *}+\mathrm{zpe}\right)$. When an implicit solvent model for water is incorporated, the hydride transfer is predicted to be much less endothermic, with the separate ions only $12.4 \mathrm{kcal} / \mathrm{mol}$ uphill from $6 /$ dimethylamine (PCM/B3LYP/6-31+G**//Onsager/B3LYP/6-31+G** + zpe), and the transition structure shifts earlier as expected from Hammond's postulate.

An alternative calculational model for the hydride transfer starts with a 1-protonated FAD model 6-1- $\mathrm{H}^{+}$, and proceeds to form $\mathrm{FADH}_{2}$ model $6-1,5-\mathrm{H}_{2}$ via transition structure 8 . The discrete protonation of $\mathrm{FAD}$ prior to subsequent steps is probably unrealistic due to its low basicity, but protonation at $\mathrm{N}^{1}$ could reasonably occur as the reaction coordinate for hydride transfer to $\mathrm{N}^{5}$ proceeds. Weighing against any concerted hydride transfer / proton transfer mechanism is the lack of a solvent isotope effect on the $\mathrm{k}_{\mathrm{cat}} / \mathrm{K}_{\mathrm{m}}$ value for sarcosine (15). Because the hydride transfer from dimethylamine to $6-1-\mathrm{H}^{+}$is more nearly thermoneutral than hydride transfer to $\mathbf{6}$, the transition structure $\mathbf{8}$ is earlier than $\mathbf{7}$. Interestingly, the barrier for hydride transfer to $6-1-\mathrm{H}^{+}$is increased by about $15 \mathrm{kcal} / \mathrm{mol}$ in the PCM solvent model compared to the gas phase, and this barrier in solution is predicted to be fairly similar to the barrier for hydride transfer to $\mathbf{6}$ in solution. (Similar results were obtained using an IPCM solvent model for water.) The increased barrier with $6-1-\mathrm{H}^{+}$in free solution may be understood by considering that the starting cation $\mathbf{6}-1-\mathrm{H}^{+}$is more stabilized by solvent than the more charge-delocalized transition structure $\mathbf{8}$.

The ion pair that would result from electron transfer between adjacent flavin and amine molecules is an electronic excited state, and is not readily modeled computationally. For this reason, the computational exploration of the electron-transfer mechanism was limited to separate discrete flavin and amine oxidation states as shown in Scheme 4. Electron transfer between dimethylamine and $\mathbf{6}$ to afford separate $\mathbf{6}^{-}$and aminium cation radical $\mathbf{9}$ in free solution is predicted to be quite uphill at $33.8 \mathrm{kcal} / \mathrm{mol}$ (PCM/UB3LYP/6-31+G**//Onsager/ $\left.\mathrm{UB} 3 \mathrm{LYP} / 6-31+\mathrm{G}^{* *}+\mathrm{zpe}\right)$. This is in reasonable agreement with an approximate separation of $1.7 \mathrm{~V}(39 \mathrm{kcal} / \mathrm{mol})$ between the oxidation potential of secondary amines (23) and the reduction potential of FAD (24). Electron transfer between flavin and amine in the enzyme could of course be much less unfavorable than this calculation suggests, owing to the possibility of flavin distortion or specific solvation by the enzyme, or ion pairing, depending on the distance between resulting ions. However, the active site of MTOX is identical to that of MSOX and the structure of the latter enzyme with dimethylglycine bound (25) shows no negatively charged residue in the active site which could form such an ion pair.

Proton transfer between $\mathbf{6}^{-\bullet}$ and $\mathbf{9}$ affords neutral radicals $\mathbf{6 - 5}-\mathrm{H} \bullet$ and $\mathbf{1 0}$. The overall formation of $6-5-\mathrm{H} \bullet / 10$ from $\mathbf{6} /$ dimethylamine is predicted to be uphill by $30.8 \mathrm{kcal} / \mathrm{mol}$, and because the two radicals are neutral, solvation by the enzyme is less likely to be able to avoid this barrier. However, the high-energy radical pair could be avoided by direct hydrogen transfer between 
$\mathbf{6}^{-\bullet}$ and 9 to afford $6-5-\mathrm{H}^{-} / N$-methyliminium cation, which can also result from a notably downhill proton transfer between $\mathbf{6}-5-\mathrm{H} \bullet$ and $\mathbf{1 0}$.

Mechanisms involving a covalently bound flavin adduct could potentially occur in two ways, either by addition of the amine to $\mathrm{C}^{4 \mathrm{a}}$ or by addition to $\mathrm{N}^{5}$ (26-30). From our previous observation of a large deuterium kinetic isotope effect of $7.2 \pm 1.0$ in this reaction (15), the formation of a discrete adduct would have to be reversible and followed by a rate-limiting elimination step. Alternatively, a concerted addition/elimination process as proposed by Miller and Edmondson (14) could account for the deuterium isotope effect. For the purpose here of interpreting the ${ }^{15} \mathrm{~N}$ kinetic isotope effect, the exploration of each of these mechanisms focused on the possible rate-limiting steps.

Scheme 5 outlines the model mechanism involving formation of adduct 11 by addition of the amine to $\mathrm{C}^{4 \mathrm{a}}$ of $\mathbf{6}$, followed by an E2 elimination to afford the $6-1,5-\mathrm{H}_{2}$ and $N$ -

methylformaldimine. The adduct $\mathbf{1 1}$ is predicted to be uphill from $\mathbf{6} /$ dimethylamine, consistent with the failure to observe adducts in simple flavin/secondary amine reactions (27). The key elimination step was modeled in two ways, using either methoxide anion to model a relatively early, tight transition state (12a) or methylamine to model a relatively late, loose transition state $(\mathbf{1 2 b})$. In either case, the elimination requires protonation at $\mathrm{N}^{1}$ to proceed, as the $\mathrm{FADH}^{-}$model 6-5- $\mathrm{H}^{-}$is a poor leaving group. Even after protonating at $\mathrm{N}^{1}$, the elimination in free solution would be extremely difficult; $\mathbf{1 2 b}$ is uphill by $59.7 \mathrm{kcal} / \mathrm{mol}$ from $\mathbf{6} /$ dimethylamine/ $\mathrm{MeNH}_{3}{ }^{+}\left(\mathrm{PCM} / \mathrm{B} 3 \mathrm{LYP} / 6-31+\mathrm{G}^{* *} / /\right.$ Onsager/B3LYP/6-31+G** + zpe).

No transition structure could be located for an intramolecular elimination from the $\mathrm{C}^{4 \mathrm{a}}$ adduct. However, an intramolecular elimination process becomes possible if adduct formation occurs by addition of the amine to $\mathrm{N}^{5}$ to afford adduct $\mathbf{1 3}$, followed by proton transfer from ammonium $\mathbf{1 3}$ to $\mathrm{N}^{5}$ (Scheme 6). The elimination transition structure $\mathbf{1 4}$ is predicted to be quite high in energy in free solution at $45.7 \mathrm{kcal} / \mathrm{mol}$, and would initially afford the $4,5-\mathrm{H}_{2}$ flavin tautomer.

Finally, transition structure $\mathbf{1 5}$ was located as a model for the concerted addition/elimination process proposed by Miller and Edmondson (14). The location of a transition structure of this type requires the combination of protonation at $\mathrm{N}^{1}$ and deprotonation of the nitrogen of the attacking amine (presumably as the process ensues); otherwise, there is no attraction of the amine to $\mathrm{C}^{4 \mathrm{a}}$, and the resulting transition structures approach $\mathbf{7}$ or $\mathbf{8}$. Structure $\mathbf{1 5}$ is predicted to be $47.0 \mathrm{kcal} / \mathrm{mol}$ above $\mathbf{6} /$ dimethylamine in free solution.

\section{Predicted Isotope Effects}

The calculated structures in the previous section provide a series of models for the prediction of the ${ }^{15} \mathrm{~N}$ isotope effect for various mechanistic possibilities. For the various hydride-transfer and elimination mechanisms, isotope effect predictions were obtained by applying conventional transition state theory to the discrete transition structures $\mathbf{7 , 8}, \mathbf{1 2 a}, \mathbf{1 2 b}, \mathbf{1 4}$, and 15. The isotope effects associated with possible electron-transfer mediated mechanisms could not be modeled in this way due to the absence of electronically ground-state transition structures. An approach to predicting these isotope effects is described in the Discussion section, but a first step toward a prediction is the calculation of the equilibrium isotope effects for formation of either cation-radical 9 or radical $\mathbf{1 0} / 6-5-\mathrm{H} \cdot$. These equilibrium isotope effects should be a poor model for the primary deuterium isotope effect in this reaction, but may approximate the secondary ${ }^{15} \mathrm{~N}$ isotope effect. Equilibrium predictions do not include a tunneling correction.

In predicting the isotope effects for the calculational models, a choice must be made of the starting material reference state between neutral dimethylamine and the protonated dimethylammonium ion. For comparison with the limiting $\mathrm{pH}$-independent ${ }^{15} \mathrm{~N}$ isotope effect 
at high $\mathrm{pH}$, dimethylamine was chosen as the reference state. This has the advantage of easing the qualitative understanding of the isotope effect predictions, without their being masked by a normal isotope effect for ammonium deprotonation. However, the choice makes no real difference in how closely predictions match with experiment. This is because the calculated equilibrium isotope effect for deprotonation of the dimethylammonium ion matches the experimental equilibrium ${ }^{15} \mathrm{~N}$ isotope effect $(1.0226 \pm 0.0001)(31-33)$ used to arrive at the experimental high-pH limiting ${ }^{15} \mathrm{~N}$ isotope effect. Dimethylammonium ion was used as the starting material reference state for the prediction of deuterium isotope effects since sarcosine would be predominantly protonated under the conditions used to measure the experimental isotope effect.

The results are summarized in Table 2. A key observation in these results is that the mechanisms involving either intramolecular or intermolecular elimination reactions as the rate-limiting step are predicted to result in ${ }^{15} \mathrm{~N}$ isotope effects significantly greater than unity. The equilibrium ${ }^{15} \mathrm{~N}$ isotope effect associated with possible intermediates in an electron-transfer mechanism are slightly inverse. More substantially inverse ${ }^{15} \mathrm{~N}$ kinetic isotope effects are predicted for the hydride transfer transition structures $\mathbf{7}$ and $\mathbf{8}$.

\section{DISCUSSION}

\section{Isotope effects}

Previous analyses of the primary deuterium isotope effect on the MTOX-catalyzed reaction have established that cleavage of the sarcosine $\mathrm{CH}$ bond is rate-limiting for turnover (15). The observation that the intrinsic deuterium isotope effect is expressed in the $\mathrm{k}_{\mathrm{cat}} / \mathrm{K}_{\mathrm{m}}$ value for sarcosine establishes that $\mathrm{CH}$ bond cleavage occurs during the first irreversible step in catalysis. While the presence of a primary deuterium isotope effect has thus proven exceedingly useful in identifying rate-limiting hydrogen transfer, the magnitude of a primary deuterium isotope effect is less useful in deciding among competing mechanisms that all involve rate-limiting hydrogen transfer. A key problem is that primary deuterium isotope effects are not readily predicted accurately due to tunneling and variational transition state effects (34). The deuterium isotope effects predicted from conventional transition state theory in Table 2 are a lower bound, as tunneling will generally increase the deuterium isotope effect. The predictions using a onedimensional Wigner tunneling correction are also likely to underestimate the isotope effect, as this correction is minimal. Because of this, comparison of the predicted deuterium isotope effects with the experimental deuterium isotope effect of about 7.0 (15) does not distinguish among the various mechanisms. The use of heavy-atom isotope effects in concert with calculational studies has the substantial advantage that tunneling plays a much smaller role. As a result, heavy-atom isotope effects are often accurately predicted when the theoretical mechanism is correct (35-38). Here, such predictions allow a detailed interpretation of the experimental ${ }^{15} \mathrm{~N}$ isotope effect.

While the proposed chemical mechanisms in Scheme 2 involve substrate with a neutral nitrogen, the zwitterionic form of sarcosine predominates over the $\mathrm{pH}$ range accessible for mechanistic study. Deprotonation of the substrate nitrogen is affected by the isotopic content of the nitrogen, such that there is a measurable ${ }^{15} \mathrm{~N}$ effect on the equilibrium constant for deprotonation. Because $\mathrm{k}_{\mathrm{cat}} / \mathrm{K}_{\mathrm{m}}$ values reflect the reaction of the free substrate and enzyme, they will include this ${ }^{15} \mathrm{~K}_{\mathrm{eq}}$, and the measured ${ }^{15}\left(\mathrm{k}_{\mathrm{cat}} / \mathrm{K}_{\mathrm{m}}\right)$ values must be corrected to obtain the ${ }^{15} \mathrm{~N}$ isotope effect on catalysis. The decrease in the measured isotope effects in Table 1 with increasing $\mathrm{pH}$ reflects this equilibrium isotope effect, in that the fraction of the substrate in the zwitterionic form decreases with increasing $\mathrm{pH}$. The accuracy of correction of the measured values to obtain the high-pH isotope effect for the reaction of the anionic substrate is obviously affected by the accuracy of the equilibrium ${ }^{15} \mathrm{~N}$ isotope effect for sarcosine protonation which is used. While the ${ }^{15} \mathrm{~N}$ isotope effect for sarcosine protonation has not been 
measured, we have calculated the equilibrium ${ }^{15} \mathrm{~N}$ isotope effect for dimethylamine/ dimethylammonium ion (Onsager/B3LYP/6-31+G**) as 1.0226. This is identical to literature values for measured equilibrium ${ }^{15} \mathrm{~N}$ isotope effects for deprotonation of glycine, alanine, and phenylalanine (31-33), so that it is likely to be quite reliable. Consequently, this value was used to correct the observed ${ }^{15}\left(\mathrm{k}_{\mathrm{cat}} / \mathrm{K}_{\mathrm{m}}\right)$ values, yielding the $\mathrm{pH}$-independent values in the last two columns in Table 1. As noted above, the ${ }^{15}\left(\mathrm{k}_{\mathrm{cat}} / \mathrm{K}_{\mathrm{m}}\right)$ values determined from sarcosine are consistently slightly greater than those determined from glycine, reflecting a systematic but unidentified experimental error. Still, the average ${ }^{15} \mathrm{~N}$ effects for oxidation of anionic sarcosine calculated independently from the residual sarcosine and the glycine product (Table 1) are much closer than the isotope effects for several of the different mechanisms under consideration. Even with the caveats above, it is clear that the ${ }^{15} \mathrm{~N}$ isotope effect for the $\mathrm{N}$ demethylation of sarcosine by MTOX is significantly inverse (less than unity), with a limiting value of 0.994-0.995 at high $\mathrm{pH}$. This value can be used for comparison with values for the isotope effect calculated for the different proposed mechanisms in Scheme 2.

\section{Covalent adducts and concerted addition/elimination}

The possibility of a $\mathrm{C}^{4 \mathrm{a}}$ adduct was supported in model reaction studies done by Mariano $(27,28)$. However, the observable amine adducts in the Mariano work were stabilized by a combination of $\mathrm{N}^{5}$ alkylation and amine deprotonation. In the absence of such stabilization, formation of a $\mathrm{C}^{4 \mathrm{a}}$ adduct is energetically unfavorable. Thus, calculational model $\mathbf{1 1}$ is 14.6 $\mathrm{kcal} / \mathrm{mol}$ above starting materials, and there is no energy minimum in calculations for the zwitterionic adduct that would result from attack of dimethylamine at $\mathrm{C}^{4 \mathrm{a}}$ of $\mathbf{6}$. Addition at $\mathrm{C}^{4 \mathrm{a}}$ would need to be aided by flavin distortion $(39,40)$ or deprotonation of the amine as it attacks $\mathrm{C}^{4 \mathrm{a}}$, or a combination of the two. Deprotonation of the amine probably cannot occur by direct transfer from the amine to $\mathrm{N}^{5}$ during addition - the required four-membered-ring transition state would be expected to be high in energy and was not locatable calculationally. Calculations were also unable to locate a transition state for unimolecular elimination of $\mathrm{N}$ methylformaldimine from $\mathbf{1 1}$. These observations suggest that both the formation of the $\mathrm{C}^{4 \mathrm{a}}$ adduct and the subsequent elimination step (as in 12) would require an as yet undefined catalytic base. While the crystal structure of MTOX is not available, a catalytic base in MSOX (sharing $41 \%$ sequence identity) has not been identified (41).

The alternative possibility of an $\mathrm{N}^{5}$ adduct is favored in calculations by greater electrophilicity at $\mathrm{N}^{5}$. While zwitterionic adduct $\mathbf{1 3}$ would be high in energy in free solution, it is at least a local energy minimum, unlike the analogous adduct resulting from attack at $\mathrm{C}^{4 \mathrm{a}}$. Elimination from an $\mathrm{N}^{5}$ adduct could also avoid the need for an external base, with imine being formed directly via a transition state resembling model 14. However, the barrier associated with 14 in free solution is very high, and the overall neutrality of this cyclic transition structure would make it difficult for an enzyme to electrostatically catalyze the elimination.

In a study of the oxidation of benzylamine analogues by MAO A, Miller and Edmondson made the intriguing observation that the reaction was accelerated by electron-withdrawing groups (14). From a $\rho$ of $\approx 2.0$, a deuterium isotope effect in a range of 6 to 13 , and the lack of observable flavin intermediates, they proposed a concerted addition/elimination mechanism. This unusual process can be modeled as in transition structure $\mathbf{1 5}$ with the proviso that the amine is deprotonated.

The ${ }^{15} \mathrm{~N}$ isotope effect results strongly weigh against any of these mechanisms. For these mechanisms involving elimination reactions as the rate-limiting step, the various calculational models lead to high-pH limit ${ }^{15} \mathrm{~N}$ isotope effects of 1.012-1.022. The predictions of normal isotope effects in these cases are readily understandable and expected on a qualitative basis. The mechanisms all involve transition states in which the nitrogen atom is undergoing a $\sigma$ bonding change, so that a primary ${ }^{15} \mathrm{~N}$ isotope effect should be observed. The observed absence 
of a primary ${ }^{15} \mathrm{~N}$ isotope effect would be conventional qualitative evidence against these mechanisms, and the calculated isotope effects strongly support the conventional interpretation.

One complicating factor in this interpretation is that the ${ }^{15} \mathrm{~N}$ isotope effect could be decreased if the amine nitrogen were protonated at the transition state. None of the elimination transition structures 12a, 12b, 14, and 15 involve protonated amine nitrogens. However, this is because these elimination steps are not viable when the amine is protonated. This may be understood at an electron-pushing level by considering that any of these eliminations involve pushing electrons away from the amine nitrogen, which is much more difficult when the nitrogen is protonated. As a result, when high-level calculations search for elimination transition structures in protonated analogs of $\mathbf{1 2 a}, \mathbf{1 2 b}, \mathbf{1 4}$, and $\mathbf{1 5}$, alternative processes intervene.

It should be noted that the barriers associated with $\mathbf{1 4}$ and $\mathbf{1 5}$ in free solution are very high, and the overall neutrality of the transition structures makes it difficult to envision how an enzyme could catalyze these cyclic elimination steps. The calculated energetics thus support the conclusion from the ${ }^{15} \mathrm{~N}$ isotope effect that mechanisms of this type are not viable.

\section{Single electron transfer}

Electron-transfer mechanisms have been frequently proposed for flavin-dependent amine oxidations (reviewed in (42)). Support for these mechanisms comes primarily from oxidation studies of cyclopropyl or cyclobutyl compounds that act as mechanism based inhibitors for MAO ((12) and references therein) and for MSOX $(43,44)$. However, it is important to note that a cyclopropyl group blocks hydride transfer, as cyclopropylidene imines are very strained, and facilitates electron transfer, as cyclopropyl groups greatly stabilize adjacent positive charge. Less strained cyclic substrates and inhibitors have failed to give the ring opening products (45-47). With the latter compounds, the lack of the ring-opening product is consistent with a non-radical mechanism.

To date, monitoring flavin reduction by substrate has failed to show any visible flavin radical spectrum in MTOX (11,15), MSOX (41,48), trimethylamine oxidase (49), lysine-specific histone demethylase-1 (50), MAO (14,51), or any of the flavin-dependent amine oxidases. In many of these cases, deuterium isotope effects have shown that $\mathrm{CH}$ bond cleavage is partially or completely rate-limiting. Therefore, if an aminium radical is utilized, its formation must be reversible and energetically unfavorable, but not rate-limiting.

Neither proton nor hydrogen transfer from 9 to $6^{-}$can be modeled computationally as these would involve electronic excited states, so theoretical calculations cannot directly calculate a ${ }^{15} \mathrm{k}$ value. To get around this problem, some simpler reactions of 9 not complicated by electronic excited states were studied. To model proton transfer from $\mathbf{9}$, the reaction of $\mathbf{9}$ with ammonia was chosen, and transition structure 16 was located (Onsager/UB3LYP/6-31+G**) for the formation of $10 / \mathrm{NH}_{4}{ }^{+}$. It is unclear how closely 16 would resemble a transition structure for proton transfer from 9 to $6^{-}$(or sarcosine cation radical to flavin semiquinone), but 16 has the virtue of being a tractable model that could also model proton transfer from 9 to an activesite base. Modeling hydrogen transfer from 9 is more difficult, and can only be done with a radical that is sufficiently electronegative to maintain radical character in the presence of $\mathbf{9}$. For this purpose, a chlorine atom was chosen, and transition structure $\mathbf{1 7}$ was located for the hydrogen transfer affording $N$-methyliminium cation $/ \mathrm{HCl}$. This transition state is notably early, as would also be expected for the downhill hydrogen transfer from 9 to $6^{-}$.

For the calculated transition structures $\mathbf{1 6}$ and $\mathbf{1 7}$, the predicted ${ }^{15} \mathrm{~N}$ kinetic isotope effect (including a tunneling correction) was 0.9963 and 0.9962 , respectively. These modestly inverse isotope effects may be understood as resulting from a strengthening of bonding to the nitrogen 
atom as proton or hydrogen transfer proceeds, as evidenced by an overall decrease in the C-N bond distances. Multiplying these kinetic isotope effects by the predicted equilibrium isotope effect for formation of $\mathbf{9}$ from Table 2 gives 0.9941 and 0.9940, respectively. Despite the simplicity of the models, both are in remarkable agreement with experiment.

An analogous analysis can be carried out for the deuterium isotope effect. Combining predicted $\mathrm{H} / \mathrm{D}$ isotope effects for $\mathbf{1 6}$ and $\mathbf{1 7}$ of 4.02 and 2.38, respectively (including the Wigner tunneling correction), with the equilibrium isotope effect of 1.38 for formation of 9 gives 5.55 and 3.28, respectively. As discussed above, these predictions with a minimal tunneling correction are likely lower bounds and cannot be considered inconsistent with the experimental H/D isotope effect of about 7.0.

An occasionally proposed mechanism, related to the electron-transfer mediated mechanisms, is rate-limiting abstraction of a hydrogen atom from the substrate, forming a carbon radical $(42,52)$. This mechanism is not directly calculable because the product is an electronic excited state; in the calculational model, it is downhill from 6-5- $-\mathrm{H}^{\bullet}+\mathbf{1 0}$ to $6-5-\mathrm{H}^{-}+N$-methyliminium cation, and a combined ground-state calculation must give the latter as a hydride transfer instead of a hydrogen transfer. To model this process, a transition structure was located for hydrogen abstraction from dimethylamine by methyl radical (see the Supporting Information). The predicted ${ }^{15} \mathrm{~N}$ and H/D isotope effects for this process are 0.9985 and 8.98 , respectively. Both isotope effects are somewhat higher than observed experimentally, and the lower-bound nature of the H/D isotope effect prediction adds significance to its being larger than that observed experimentally. While the simplicity of the calculational model in this case makes it difficult to reach a firm conclusion on the direct hydrogen-transfer mechanism, the isotope effects cannot be said to provide support for the mechanism as in the cases above. In addition, considering the energetic preference for 6-5- $\mathrm{H}^{-}+N$-methyliminium cation over $6-5-\mathrm{H} \bullet+10$, and a presumed greater difficulty for the enzyme to stabilize the latter neutral molecules over the former charged species, the calculated energetics add weight against a direct hydrogen transfer from starting amine.

Overall, this analysis of the isotope effects and the close correspondence of predicted and experimental ${ }^{15} \mathrm{~N}$ kinetic isotope effects would appear to support rate-limiting proton or hydrogen transfer after an initial electron-transfer. However, it will be seen that the results provide equal support for a hydride-transfer mechanism.

\section{Hydride transfer}

A concerted hydride transfer is the simplest proposed mechanism for flavin-dependent amine oxidation, and is frequently accepted as the chemical mechanism for the thoroughly studied D-amino acid oxidase (13). This mechanism is most consistent with the lack of visible intermediate flavin species during sarcosine oxidation (15), as it requires no intermediates. The absence of an observable intermediate does not exclude covalent-adduct and electron-transfer mechanisms, as intermediates could be too short-lived to be observed, but it does weigh against such mechanisms, particularly since the mechanisms involve intermediate flavin species prior to the rate-limiting $\mathrm{CH}$ bond cleavage.

The evaluation of the hydride-transfer mechanism here is based on the comparison of the experimental ${ }^{15} \mathrm{~N}$ isotope effect of $0.994-0.995$ versus those predicted for model transition structures $\mathbf{7}$ and $\mathbf{8}$. The ${ }^{15} \mathrm{~N}$ isotope effects predicted for $\mathbf{7}$ and $\mathbf{8}$ are notably inverse at 0.992 and 0.993 , respectively. At first glance, these inverse isotope effects may seem surprising, since the nitrogen is undergoing a substantial bonding change in the process. However, heavy-atom isotope effects associated with $\pi$-bonding changes depend on the nature of the bonding change. When there is little change in total $\pi$-bond order, the isotope effect is very small. For example, the central carbons of a diene in a Diels-Alder reaction do not exhibit a significant ${ }^{13} \mathrm{C}$ isotope 
effect (53). In reactions of $\mathrm{O}_{2}$, the direction of the isotope effect can be associated with the direction of change in the $\mathrm{O}_{2}$ bond strength - a weakening of the $\mathrm{O}-\mathrm{O}$ bond leads to a normal isotope effect, while a strengthening leads to an inverse isotope effect (54). In $\mathbf{7}$ and $\mathbf{8}$, there is a shortening of the $\mathrm{C}-\mathrm{N}$ bond as the hydride is transferred, leading to a tighter potential energy well around the nitrogen atom, leading to the inverse isotope effects.

The agreement of the predicted ${ }^{15} \mathrm{~N}$ isotope effects for hydride-transfer mechanisms with experiment is striking. Considering the experimental uncertainty discussed above, the agreement must be considered at least as good as that for the electron-transfer mechanisms. It may be argued that the agreement is of greater significance in the case of the hydride-transfer mechanisms, as $\mathbf{7}$ and $\mathbf{8}$ are straight-forward models for hydride transfer while the prediction of isotope effects for electron-transfer mechanisms was necessarily a contrived process.

However, the observed ${ }^{15} \mathrm{~N}$ isotope effect can clearly be taken as supporting either mechanism.

Although the energetics for the calculational model mechanisms are not directly related to those for possible enzyme-catalyzed mechanisms, some comment can be made on the energetic feasibility of the hydride transfer versus alternative possibilities. The barriers associated with 7 and 8 in free solution are $10-15 \mathrm{kcal} / \mathrm{mol}$ higher than those for the enzymatic reaction, but a direct uncatalyzed hydride transfer should occur at an observable rate at ambient temperature and should be reasonably facile at elevated temperature. The hydride transfer should be readily catalyzed by an enzyme by hydrogen bonding or proton transfer to $\mathrm{N}^{1}$, and the greatly decreased gas-phase barrier for $\mathbf{8}$ suggests that proton transfer ought to be most effective in a non-polar pocket. Consistent with such a model, many flavoproteins oxidases have a positively charged residue or the positive end of a helix near the flavin $\mathrm{N}^{1}(55,56)$. The enzyme could also ease the hydride transfer by electrostatically stabilizing the incipient iminium ion. Alternatively, if the flavin is distorted away from planarity by the enzyme, this should facilitate the hydride transfer, just as it facilitates electron transfer. In products $6-5-\mathrm{H}^{-}$and $6-1,5-\mathrm{H}_{2}$, the flavin rings are bent approximately $20^{\circ}$ from planarity (the $\mathrm{C}^{4}-\mathrm{N}^{5}-\mathrm{C}^{6}$ angles are approximately $160^{\circ}$ ) while the starting flavin is planar, so enzymes that pre-bend the flavin will lower the barrier to hydride transfer. Overall, the calculated facility of the reaction in free solution and the expected ease of its catalysis support the viability of the hydride-transfer mechanism.

Electron transfer to form $6^{-} / 9$ is predicted to have a higher barrier in free solution than hydride transfer. In the actual mechanism, this electron transfer would necessarily precede a yet higher barrier for rate-limiting proton or hydrogen transfer to account for the observed primary deuterium isotope effect. The combination of the calculated energetics and the primary H/D isotope effect thus adds to an energetic argument against the electron-transfer mechanism. However, it is impossible to dismiss the electron-transfer mechanism on this basis, as MTOX might promote electron transfer either by electrostatic stabilization of the charged intermediates or by flavin distortion.

\section{CONCLUSIONS}

The computational predictability of heavy-atom kinetic isotope effects has often allowed their detailed interpretation beyond conventional qualitative considerations. In the case of sarcosine oxidation by MTOX, the interpretation of the observed ${ }^{15} \mathrm{~N}$ kinetic isotope effect of approximately 0.994 based on calculated isotope effects is not unique. Both a direct hydridetransfer mechanism and reversible electron transfer followed by rate-limiting proton or hydrogen transfer can account for the observed isotope effect. However, the isotope effects predicted for models of mechanisms involving covalent adducts or concerted addition/ elimination are significantly different from the experimental value and thus strongly disfavor these mechanisms. In concert with the absence of observable intermediates and the poor calculated energetics for these mechanisms, we conclude that their consideration for sarcosine 
oxidation by MTOX can be discounted. The calculated energetics for model reactions add some support for the hydride-transfer mechanism, as the enzyme need only modestly lower the barrier for the reaction versus that in free solution. The electron-transfer mechanisms in contrast would require somewhat greater energies, and it would be surprising if this left a proton or hydrogen transfer step as rate-limiting.

\section{References}

1. Settembre EC, Dorrestein PC, Park J, Augustine AM, Begley TP, Ealick SE. Structural and mechanistic studies on thiO, a glycine oxidase essential for thiamin biosynthesis in Bacillus subtilis. Biochemistry 2003;42:2971-2981. [PubMed: 12627963]

2. Shi Y, Lan F, Matson C, Mulligan P, Whetstine JR, Cole PA, Casero RA. Histone demethylation mediated by the nuclear amine oxidase homolog LSD1. Cell 2004;119:941-953. [PubMed: 15620353]

3. Mattevi A, Vanoni MA, Todone F, Rizzi M, Teplyakov A, Coda A, Bolognesi M, Curti B. Crystal structure of D-amino acid oxidase: A case of active site mirror-image convergent evolution with flavocytochrome $b_{2}$. Proc Natl Acad Sci USA 1996;93:7496-7501. [PubMed: 8755502]

4. Trickey P, Wagner MA, Jorns MS, Mathews FS. Monomeric sarcosine oxidase: structure of a covalently flavinylated amine oxidizing enzyme. Structure 1999;7:331-345. [PubMed: 10368302]

5. Binda C, Newton-Vinson P, Hubalek F, Edmondson DE, Mattevi A. Structure of human monoamine oxidase B, a drug target for the treatment of neurological disorders. Nature Struct Biol 2002;9:22-26. [PubMed: 11753429]

6. Binda C, Coda A, Angelini R, Federico R, Ascenzi P, Mattevi A. A 30 Å long U-shaped catalytic tunnel in the crystal structure of polyamine oxidase. Structure 1999;7:265-276. [PubMed: 10368296]

7. Stavropoulos P, Blobel G, Hoelz A. Crystal structure and mechanism of human lysine-specific demethylase-1. Nat Struct Mol Biol 2006;13:626-632. [PubMed: 16799558]

8. Pawelek PD, Cheah J, Coulombe R, Macheroux P, Ghisla S, Vrielink A. The structure of L-amino acid oxidase reveals the substrate trajectory into an enantiomerically conserved active site. EMBO J 2000;19:4204-4215. [PubMed: 10944103]

9. Kurtz KA, Rishavy MA, Cleland WW, Fitzpatrick PF. Nitrogen isotope effects as probes of the mechanism of D-amino acid oxidase. J Am Chem Soc 2000;122:12896-12897.

10. Koyama Y, Ohmori H. Nucleotide sequence of the Escherichia coli solA gene encoding a sarcosine oxidase-like protein and characterization of its product. Gene 1996;181:179-183. [PubMed: 8973328]

11. Khanna P, Schuman Jorns M. N-Methyltryptophan oxidase from Escherichia coli: reaction kinetics with N-methyl amino acid and carbinolamine substrates. Biochemistry 2001;40:1451-9. [PubMed: 11170473]

12. Scrutton NS. Chemical aspects of amine oxidation by flavoprotein enzymes. Nat Prod Rep 2004;21:722-730. [PubMed: 15565251]

13. Fitzpatrick PF. Carbanion versus hydride transfer mechanisms in flavoprotein-catalyzed dehydrogenations. Bioorg Chem 2004;32:125-139. [PubMed: 15110192]

14. Miller JR, Edmondson DE. Structure-activity relationships in the oxidation of para-substituted benzylamine analogues by recombinant human liver monoamine oxidase A. Biochemistry 1999;38:13670-13683. [PubMed: 10521274]

15. Ralph EC, Fitzpatrick PF. pH and kinetic isotope effects on sarcosine oxidation by Nmethyltryptophan oxidase. Biochemistry 2005;44:3074-3081. [PubMed: 15723552]

16. Frisch, MJ.; Trucks, GW.; Schlegel, HB.; Scuseria, GE.; Robb, MA.; Cheeseman, JR.; Montgomery, JA., Jr; Vreven, T.; Kudin, KN.; Burant, JC.; Millam, JM.; Iyengar, SS.; Tomasi, J.; Barone, V.; Mennucci, B.; Cossi, M.; Scalmani, G.; Rega, N.; Petersson, GA.; Nakatsuji, H.; Hada, M.; Ehara, M.; Toyota, K.; Fukuda, R.; Hasegawa, J.; Ishida, M.; Nakajima, T.; Honda, Y.; Kitao, O.; Nakai, H.; Klene, M.; Li, X.; Knox, JE.; Hratchian, HP.; Cross, JB.; Bakken, V.; Adamo, C.; Jaramillo, J.; Gomperts, R.; Stratmann, RE.; Yazyev, O.; Austin, AJ.; Cammi, R.; Pomelli, C.; Ochterski, JW.; Ayala, PY.; Morokuma, K.; Voth, GA.; Salvador, P.; Dannenberg, JJ.; Zakrzewski, VG.; Dapprich, S.; Daniels, AD.; Strain, MC.; Farkas, O.; Malick, DK.; Rabuck, AD.; Raghavachari, K.; Foresman, JB.; Ortiz, JV.; Cui, Q.; Baboul, AG.; Clifford, S.; Cioslowski, J.; Stefanov, BB.; Liu, G.; Liashenko, 
A.; Piskorz, P.; Komaromi, I.; Martin, RL.; Fox, DJ.; Keith, T.; Al-Laham, MA.; Peng, CY.; Nanayakkara, A.; Challacombe, M.; Gill, PMW.; Johnson, B.; Chen, W.; Wong, MW.; Gonzalez, C.; Pople, JA. Gaussian, Inc; Wallingford, CT: 2004.

17. Onsager L. Electric moments of molecules in liquids. J Am Chem Soc 1936;58:1486-1493.

18. Tomasi J, Persico M. Molecular interactions in solution: an overview of methods based on continuous distributions of the solvent. Chem Rev 1994;94:2027-2094.

19. Bondi A. van der Waals volumes and radii. J Phys Chem 1964;68:441-451.

20. Bigeleisen J, Goeppert-Mayer M. Calculation of equilibrium constants for isotope exchange reactions. J Chem Phys 1947;15:261-267.

21. Bigeleisen J. The relative reaction velocities of isotopic molecules. J Chem Phys 1949;17:675-678.

22. Wigner E. Crossing of potential thresholds in chemical reactions. Z Phys Chem B 1932;19:203-216.

23. Fu Y, Liu L, Yu H-Z, Wang Y-M, Guo Q-X. Quantum chemical predictions of absolute standard redox potentials of diverse organic molecules and free radicals in acetonitrile. J Amer Chem Soc $2005 ; 127$

24. Smith ET, Davis CA, Barber MJ. Voltammetric simulations of multiple electron transfer/proton transfer coupled reactions: flavin adenine dinucleotide as a model system. Anal Biochem 2003;323:114-121. [PubMed: 14622965]

25. Wagner MA, Trickey P, Chen Z-w, Mathews FS, Jorns MS. Monomeric sarcosine oxidase: 1. Flavin reactivity and active site binding determinants. Biochemistry 2000;39:8813-8824. [PubMed: 10913292]

26. Brown LE, Hamilton GA. Some model reactions and a general mechanism for flavoenzyme-catalyzed dehydrogenations. J Am Chem Soc 1970;92:7225-7227. [PubMed: 5486616]

27. Kim JM, Bogdan MA, Mariano PS. Mechanistic analysis of the 3-methyllumiflavin-promoted oxidative deamination of benzylamine. A potential model for monoamine oxidase catalysis. J Am Chem Soc 1993;115:10591-10595.

28. Kim JM, Hoegy SE, Mariano PS. Flavin chemical models for monoamine oxidase inactivation by cyclopropylamines, a-silylamines, and hydrazines. J Am Chem Soc 1995;117:100-105.

29. Kurtz KA, Fitzpatrick PF. pH and secondary kinetic isotope effects on the reaction of D-amino acid oxidase with nitroalkane anions: Evidence for direct attack on the flavin by carbanions. J Am Chem Soc 1997;119:1155-1156.

30. Binda C, Li M, Hubalek F, Restelli N, Edmondson D, Mattevi A. Insights into the mode of inhibition of human mitochondrial monoamine oxidase B from high-resolution crystal structures. Proc Nat Acad Sci USA 2003;100:9750-9755. [PubMed: 12913124]

31. Rabenstein DL, Mariappan SVS. Determination of ${ }^{15} \mathrm{~N}$ Isotope Effects on the Acid-Base Equilibria of Amino Groups in Amino Acids by ${ }^{13}$ C NMR. J Org Chem 1993;58:4487-4489.

32. Pehk T, Kiirend E, Lippmaa E, Ragnarsson U, Grehn L. Determination of isotope effects on acidbase equilibria by ${ }^{13}$ C NMR spectroscopy. J Chem Soc Perkin Trans 1997;2:445-450.

33. Ralph EC, Anderson MA, Cleland WW, Fitzpatrick PF. Mechanistic studies of the flavoenzyme tryptophan 2-monooxygenase: Deuterium and ${ }^{15} \mathrm{~N}$ kinetic isotope effects on alanine oxidation by an L-amino acid oxidase. Biochemistry 2006;45:15844-15852. [PubMed: 17176107]

34. Lu, D-h; Maurice, D.; Truhlar, DG. What is the effect of variational optimization of the transition state on alpha-deuterium secondary kinetic isotope effects? A prototype: $\mathrm{CD}_{3} \mathrm{H}+\mathrm{H}-->\mathrm{CD}_{3}+\mathrm{H}_{2}$. J Am Chem Soc 1990;112:6206-6214.

35. Singleton DA, Merrigan SR, Liu J, Houk KN. Experimental geometry of the epoxidation transition state. J Am Chem Soc 1997;119:3385-3386.

36. Meyer MP, DelMonte AJ, Singleton DA. Reinvestigation of the isotope effects for the Claisen and aromatic Claisen rearrangements: The nature of the Claisen transition state. J Am Chem Soc 1999;121:10865-10875.

37. DelMonte AJ, Haller J, Houk KN, Sharpless KB, Singleton DA, Strassner T, Thomas AA. Experimental and theoretical kinetic isotope effects for asymmetric dihydroxylation. Evidence supporting a rate-Limiting “(3 + 2)” cycloaddition. J Am Chem Soc 1997;119:9907-9908. 
38. Beno BR, Houk KN, Singleton DA. Synchronous or asynchronous? An "experimental" transition state from a direct comparison of experimental and theoretical kinetic isotope effects for a DielsAlder reaction. J Am Chem Soc 1996;118:9984-9985.

39. Edmondson DE, Binda C, Mattevi A. The FAD binding sites of human monoamine oxidases A and B. Neurotoxicology 2004;25:63-72. [PubMed: 14697881]

40. Trickey P, Basran J, Lian L-Y, Chen Z, Barton JD, Sutcliffe MJ, Scrutton NS, Mathews FS. Structural and biochemical characterization of recombinant wild type and a C30A mutant of trimethylamine dehydrogenase from Methylophilus methylotrophus (sp. W3A1). Biochemistry 2000;39:7678-7688. [PubMed: 10869173]

41. Zhao G, Song H, Chen Z, Mathews S, Jorns MS. Monomeric sarcosine oxidase: role of histidine 269 in catalysis. Biochemistry 2002;41:9751-9764. [PubMed: 12146941]

42. Rigby SE, Hynson RM, Ramsay RR, Munro AW, Scrutton NS. A stable tyrosyl radical in monoamine oxidase A. J Biol Chem 2005;280:4627-4631. [PubMed: 15556933]

43. Chen ZW, Zhao G, Martinovic S, Jorns MS, Mathews FS. Structure of the sodium borohydridereduced $\mathrm{N}$-(cyclopropyl)glycine adduct of the flavoenzyme monomeric sarcosine oxidase. Biochemistry 2005;44:15444-15450. [PubMed: 16300392]

44. Zhao G, Qu J, Davis FA, Jorns MS. Inactivation of monomeric sarcosine oxidase by reaction with N-(cyclopropyl)glycine. Biochemistry 2000;39:14341-14347. [PubMed: 11087383]

45. Rimoldi JM, Puppali SG, Isin E, Bissel P, Khalil A, Castagnoli N Jr. A novel and selective monoamine oxidase B substrate. Bioorg Med Chem 2005;13:5808-5813. [PubMed: 15993094]

46. Wang X, Silverman RB. Monoamine oxidase-catalyzed oxidation of endo,endo-2-amino-6-[(Z)-2' phenyl] ethylicyclo[2.2.1] heptane, a potential probe for a radical cation intermediate. Bioorg Med Chem 2000;8:1645-1651. [PubMed: 10976512]

47. Wang X, Silverman RB. 2-(Iodoethenyl) benzylamines as potential probes for radical intermediates formed during monoamine oxidase catalyzed oxidations. J Org Chem 1998;63:7357-7363. [PubMed: 11672383]

48. Wagner MA, Jorns MS. Monomeric sarcosine oxidase: 2. Kinetic studies with sarcosine, alternate substrates, and a substrate analogue. Biochemistry 2000;39:8825-8829. [PubMed: 10913293]

49. Jang MH, Basran J, Scrutton NS, Hille R. The reaction of trimethylamine dehydrogenase with trimethylamine. J Biol Chem 1999;274:13147-13154. [PubMed: 10224069]

50. Forneris F, Binda C, Vanoni MA, Mattevi A, Battaglioli E. Histone demethylation catalysed by LSD1 is a flavin-dependent oxidative process. FEBS Lett 2005;579:2203-2207. [PubMed: 15811342]

51. Nandigama RK, Miller JR, Edmondson D. Loss of serotonin oxidatin as a component of the altered substrate specificity in the Y444F mutant of recombinant human liver MAO A. Biochemistry 2001;40:14839-14846. [PubMed: 11732903]

52. Bannister AJ, Schneider R, Kouzarides T. Histone methylation: dynamic or static? Cell 2002;109:801-806. [PubMed: 12110177]

53. Singleton DA, Schulmeier BE, Hang C, Thomas AA, Leung SW, Merrigan SR. Isotope effects and the distinction between synchronous, asynchronous, and stepwise Diels-Alder reactions. Tetrahedron 2001;57:5149-5160.

54. Lanci MP, Brinkley DW, Stone KL, Smirnov VV, Roth JP. Structures of transition states in metalmediated $\mathrm{O}_{2}$-activation reactions. Angew Chem Int Ed 2005;44:7273-7276.

55. Massey V, Ghisla S, Moore EG. 8-mercaptoflavins as active site probes of flavoenzymes. J Biol Chem 1979;254:9640-9650. [PubMed: 39928]

56. Fraaije MW, Mattevi A. Flavoenzymes: diverse catalysts with recurrent features. TIBS 2000;25:126132. [PubMed: 10694883]

\section{Abbreviations}

\section{MTOX}

$N$-methyltryptophan oxidase

MSOX

monomeric sarcosine oxidase 
MAO

monoamine oxidase

DFT

density functional theory

IRMS

isotopic ratio mass spectrometry

PCM

polarizable continuum model

IPCM

isodensity-surface polarized continuum model 


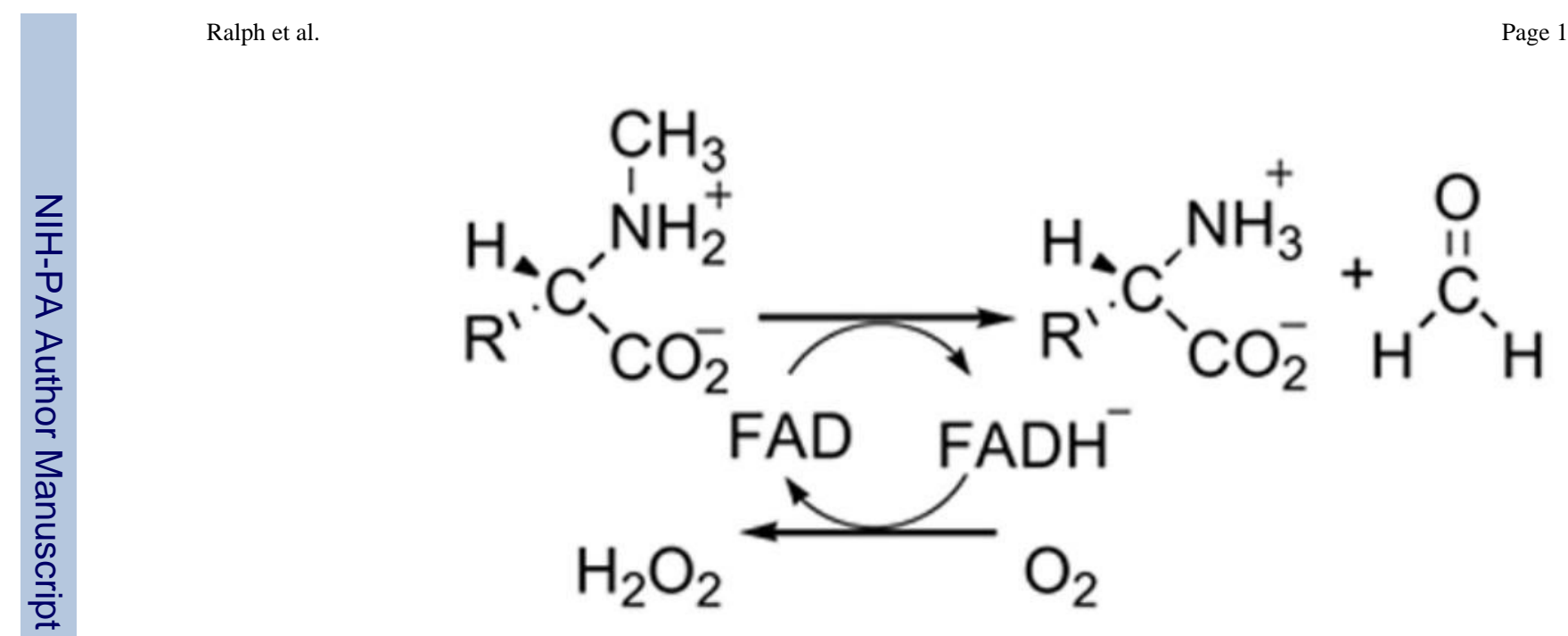

Scheme 1. 

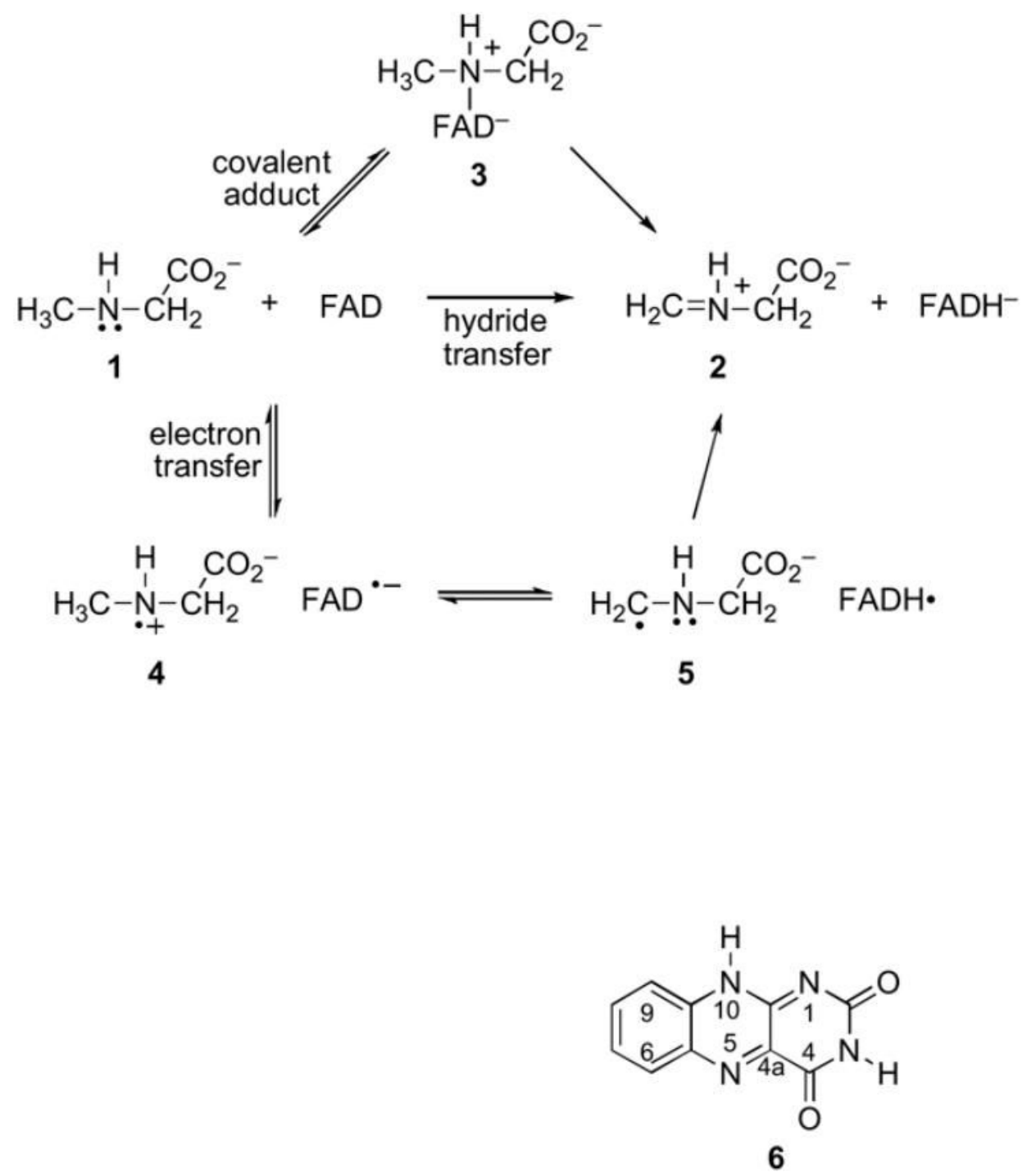

Scheme 2. 

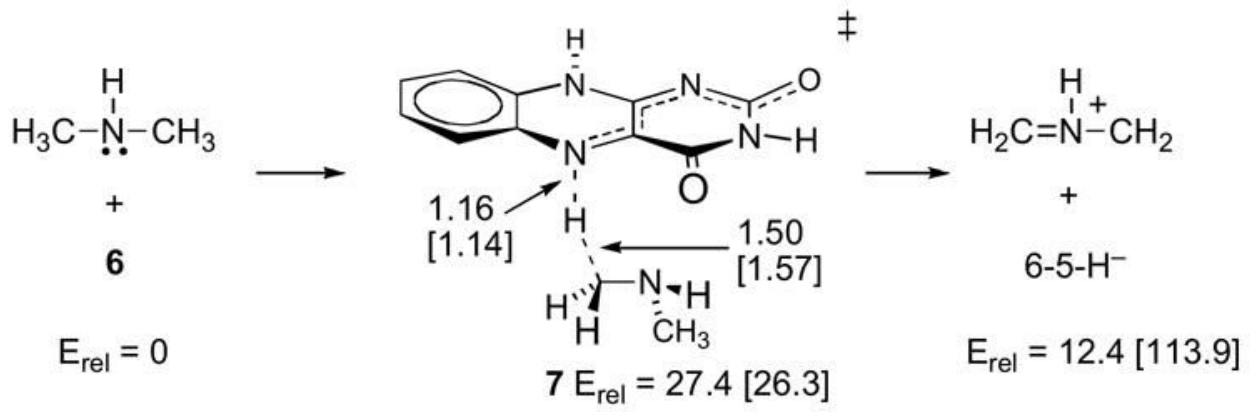

B3LYP/6-31+G** + solvent model [gas phase]

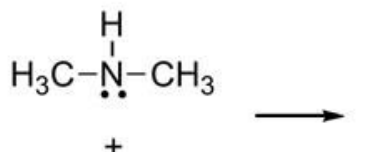

6-1- $\mathrm{H}^{+}$

$E_{\text {rel }}=0$

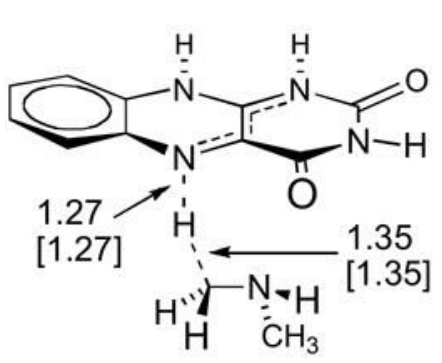

$8 \mathrm{E}_{\mathrm{rel}}=23.4[8.2]$

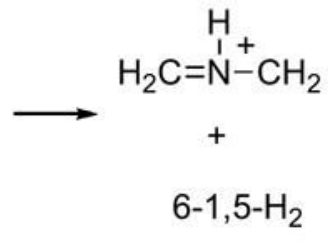

$E_{\text {rel }}=1.4[11.9]$

Scheme 3. 


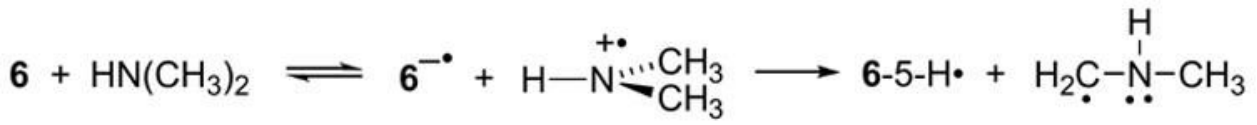

$$
\begin{aligned}
& 9 \\
& \mathrm{E}_{\mathrm{rel}}=0 \quad \mathrm{E}_{\mathrm{rel}}=33.8[135.7] \\
& \text { B3LYP/6-31+G** solvent model } \\
& \text { [gas phase] } \\
& 10 \\
& E_{\text {rel }}=30.8[30.3] \\
& \because \downarrow
\end{aligned}
$$

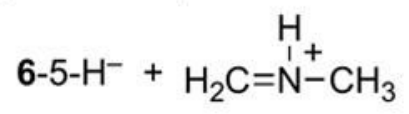

$$
\begin{aligned}
& \mathrm{E}_{\mathrm{rel}}=12.4 \text { [113.9] }
\end{aligned}
$$

Scheme 4. 


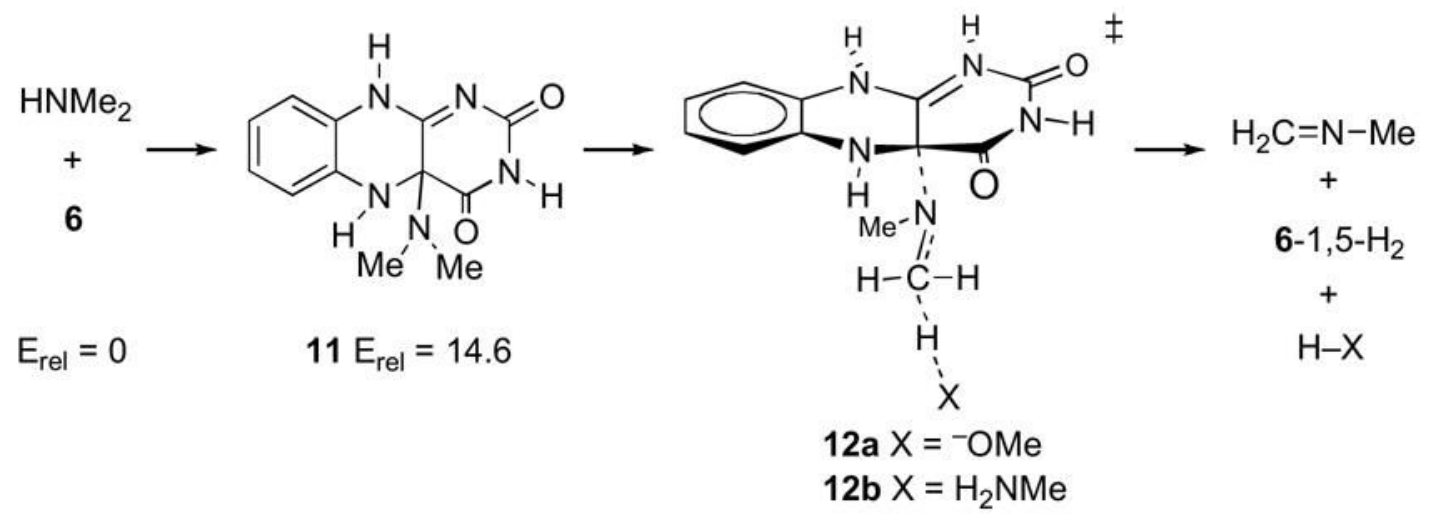

Scheme 5. 

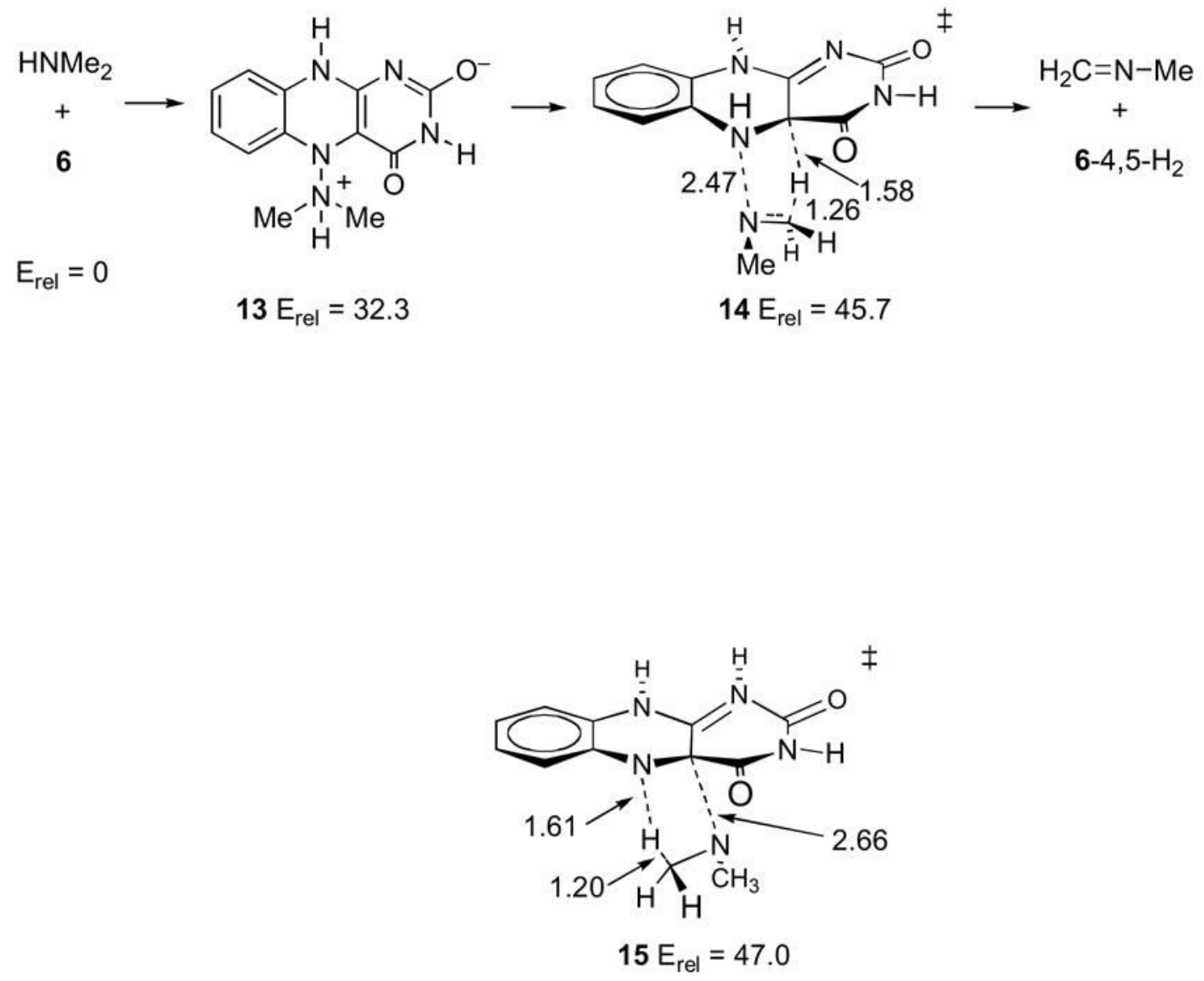

Scheme 6. 


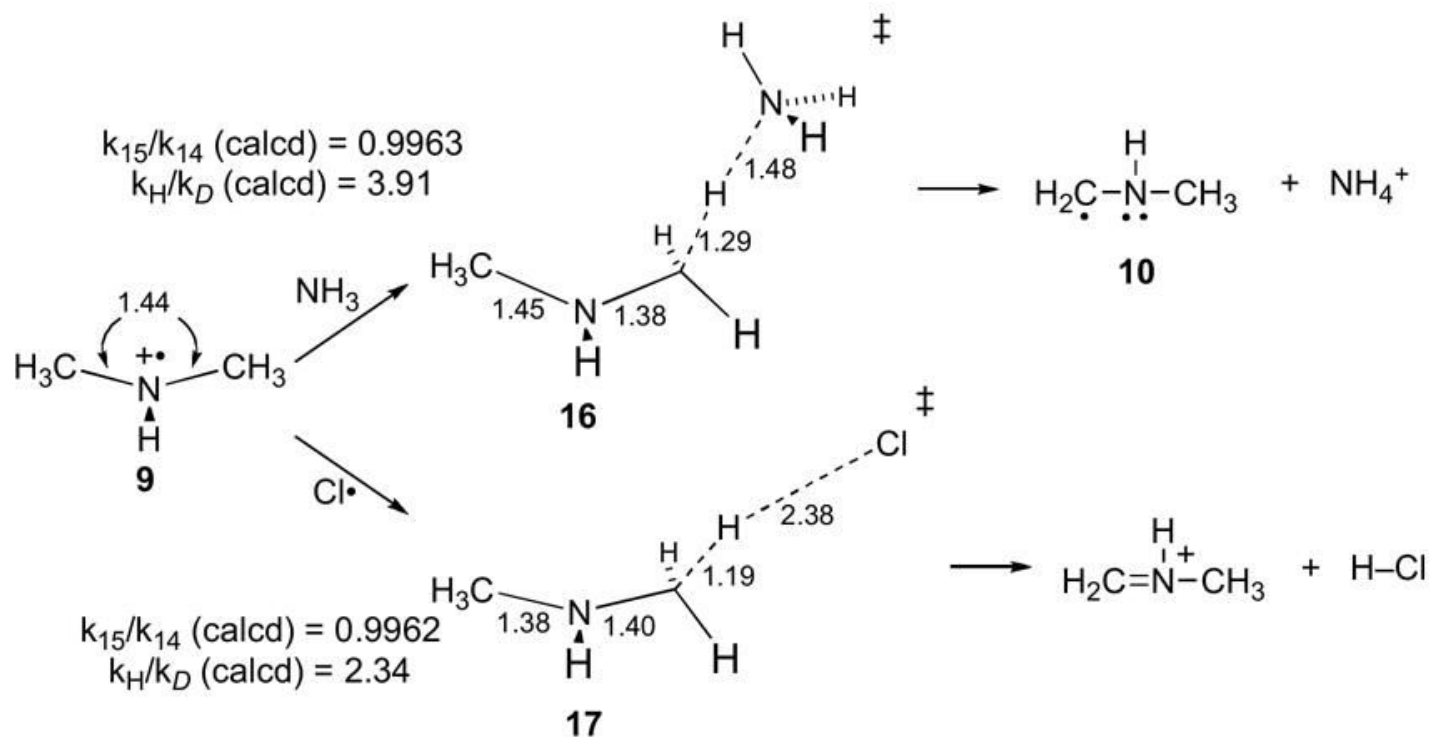

Scheme 7. 
Table 1

Observed and corrected ${ }^{15}\left(\mathrm{k}_{\text {cat }} / \mathrm{K}_{\mathrm{m}}\right)$ values. ${ }^{a}$

\begin{tabular}{|c|c|c|c|c|}
\hline pH & ${ }^{15} \mathrm{KIE}_{\mathrm{obs},} \mathrm{S}$ & ${ }^{15} \mathrm{KIE}_{\mathrm{obs},}, \mathrm{G}$ & ${ }^{15} k_{\mathrm{S}}$ & ${ }^{15} \mathbf{k}_{\mathrm{G}}$ \\
\hline 7.5 & 1.0185 & 1.0166 & 0.9960 & 0.9942 \\
\hline 7.5 & 1.0180 & 1.0168 & 0.9955 & 0.9943 \\
\hline 8.0 & 1.0172 & 1.0157 & 0.9948 & 0.9933 \\
\hline 8.5 & 1.0180 & 1.0157 & 0.9958 & 0.9935 \\
\hline 8.5 & 1.0171 & 1.0166 & 0.9949 & 0.9944 \\
\hline 8.5 & 1.0171 & 1.0168 & 0.9950 & 0.9946 \\
\hline 9.0 & 1.0165 & 1.0154 & 0.9950 & 0.9940 \\
\hline 9.0 & 1.0166 & 1.0151 & 0.9951 & 0.9937 \\
\hline 9.5 & 1.0141 & 1.0129 & 0.9945 & 0.9934 \\
\hline 9.5 & 1.0140 & 1.0130 & 0.9944 & 0.9934 \\
\hline 9.7 & 1.0128 & 1.0122 & 0.9946 & 0.9940 \\
\hline 9.7 & 1.0137 & 1.0123 & 0.9955 & 0.9941 \\
\hline 9.8 & 1.0129 & 1.0117 & 0.9955 & 0.9944 \\
\hline 9.8 & 1.0132 & 1.0117 & 0.9958 & 0.9943 \\
\hline average & & & $0.9952 \pm 0.0005$ & $0.9940 \pm 0.0004$ \\
\hline
\end{tabular}

$a_{\text {The }} 15_{\mathrm{N}}$ abundances were determined as described in the Experimental Procedures and used in equations 1 and 2 to calculate the observed isotope effects

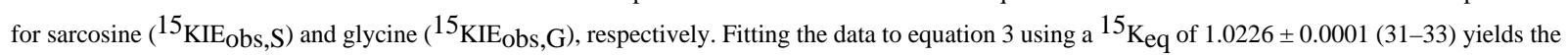
$\mathrm{pH}$-independent isotope effects shown as $15_{\mathrm{k}_{\mathrm{S}}}$ and $15_{\mathrm{k}_{\mathrm{G}}}$ for sarcosine and glycine, respectively. 
Table 2

Predicted ${ }^{15} \mathrm{~N}\left(\mathrm{k}_{15 \mathrm{~N}} / \mathrm{k}_{14 \mathrm{~N}}\right.$, high-pH limit) or deuterium $\left(\mathrm{k}_{\mathrm{H}} / \mathrm{k}_{\mathrm{D}}\right)$ kinetic isotope effects at $25{ }^{\circ} \mathrm{C}$.

\begin{tabular}{|c|c|c|c|c|}
\hline Structure & ${ }^{15} \mathrm{~N}$ isotope effect & ${ }^{2} \mathrm{H}$ isotope effect ${ }^{a}$ & $\begin{array}{l}{ }^{15} \mathrm{~N} \text { isotope effect/ } \\
\text { Wigner correction }\end{array}$ & $\begin{array}{c}{ }^{2} \mathrm{H} \text { isotope effect/Wigner } \\
\text { correction }\end{array}$ \\
\hline 7 & 0.9921 & 4.00 & 0.9927 & 4.77 \\
\hline 8 & 0.9932 & 4.71 & 0.9942 & 6.17 \\
\hline 9 & $0.9978^{b}$ & $1.38^{b}$ & --- & --- \\
\hline $10 / 6-5-\mathrm{H} \bullet$ & $0.9962^{b}$ & $1.22^{b}$ & ---- & ---- \\
\hline $12 \mathrm{a}$ & 1.0116 & 6.69 & 1.0130 & 9.20 \\
\hline $12 b$ & 1.0223 & 4.16 & 1.0250 & 4.29 \\
\hline 14 & 1.0139 & 4.07 & 1.0151 & 4.45 \\
\hline 15 & 1.0197 & 3.24 & 1.0203 & 3.34 \\
\hline
\end{tabular}

